Book Review

\title{
Sport, Social Exclusion and the Forgotten Art of Researching Poverty: Book Review of Sport and Social Exclusion (2nd ed.). By Mike Collins and Tess Kay. New York: Routledge, 2014, 320 pp.; ISBN: 978-0-415-56880-7.
}

\author{
Reinhard Haudenhuyse \\ Sport and Society Research Unit, Department of Sports Policy and Management, Vrije Universiteit Brussel, \\ 1050 Brussels, Belgium; E-Mail: reinhard.haudenhuyse@vub.ac.be
}

Submitted: 3 December 2014 | Published: 25 June 2015

\begin{abstract}
Book Review of Sport and Social Exclusion (2nd ed.). By Mike Collins and Tess Kay. New York: Routledge, 2014,320 pp.; ISBN: 978-0-415-56880-7.
\end{abstract}

\section{Keywords}

leisure research; poverty; social exclusion; sport

\section{Issue}

This book review is part of the special issue "Sport for Social Inclusion: Critical Analyses and Future Challenges", edited by Dr. Reinhard Haudenhuyse (Vrije Universiteit Brussel, Belgium) and Professor Marc Theeboom (Vrije Universiteit Brussel, Belgium).

(C) 2015 by the author; licensee Cogitatio (Lisbon, Portugal). This article is licensed under a Creative Commons Attribution 4.0 International License (CC BY).

Time and time again the poor have low or narrow participation in sport, but also in a much wider range of leisure, and this is even more true if they are female, non-white and disabled. (Collins, 2014, p. 9)

\section{Time for a Second Edition}

Roughly 10 years after Mike Collins' seminal and ground-breaking book on sport and social exclusion, a new generation of sport scientists, practitioners, policymakers and students are offered an update with this second edition. Although the book draws heavily on research and policy insights from the United Kingdom, the materials offered to the reader on exclusionary processes embedded in the domain of sports are applicable and relevant to other contexts and regions. A quick walk through the table of contents shows that the second edition has been extended to include twice the original number of case studies $(n: 8)$ illustrating the book's major themes. This makes the book an even more valuable resource for practitioners and policymakers. Reviewing the references further shows that a substantial amount of new references have been added after the publication year of the book's first edition.

After Mike Collins' passing in the summer of 2014, this book reflects the legacy of a seasoned, wellexperienced researcher who has continuously stressed that sports needs to be understood as part of social life, and therefore inevitably a co-carrier of processes of social exclusion. Moreover, Haudenhuyse, Theeboom and Nols (2013) argued that there is a danger of viewing sport as a versatile instrument for social inclusion. This does not imply however that those active in the domains of sport can "sit on the bench" when social exclusion takes the field. As Collins $(2003,2014)$ formulated: "The sports world can leave inclusion to others and be part of the problem of an unequal society, or take hard decisions and demanding steps to be part of the moves to inclusion and be part of the solution".

\section{Grand Tour Questions}

According to Chenail (2010), describing one chapter after another is not a book review, since it is the task of a 
reviewer to offer readers more than a mere recapping of the book's text. Readers who are interested in a chapter summary, are advised to read the last and concluding chapter 12 of the book. So what insight has the book to offer in terms of better understanding the relationship between sport and social exclusion? What is, from a policy perspective, the best way to tackle exclusion from sport and society in the future? What are the lessons that will enable sport to become more an agent of change, instead of merely a mirror of an unequal society? These are the central "grand tour questions" (Chenail, 2010) that I will use as focal points in my book review. Drawing on the information and materials that the book provides, I will try to answer these questions.

\section{Critical Insights}

The most important insight in the books is that exclusion from sport is real and that at its core is poverty. This is the central message, perhaps mantra, which runs through the book. On a more critical note, we could ask ourselves that, if poverty is at the core of social exclusion (and the book), why the author did not chose to include "poverty" in the title of the book? Coalter (2012) argued that since "class" is no longer an option to describe inequality and disadvantage in society, new terms needed to be invented. He continues stating that social exclusion and the socially excluded were the code for "poverty" and "the poor" (Coalter, 2012, p. 6).

Poverty limits and excludes people from leisure, and money is listed as the most significant constraint Money to pay for the costs of playing sports, childcare, transport and so forth. Although limited survey data and the international research literature clearly shows that there is a social and income gradient in sport participation, the author stated that we still know little about the relationship between poverty and participation in sport. Collins opined that leisure studies as a still relatively young academic field has been criticised for many shortcomings, but not for ignoring poverty. He admits that as a sport researcher writing about poverty is difficult, as leisure studies have produced only a few discussions of income and poverty, and at the same time mainstream poverty studies have mainly ignored or neglected leisure issues, in particular sport. Of course there are others excluded by factors of racism, ageism, gender-blindness, disability, and geographic isolation but the bulk of people excluded are also poor (p. 55). Poverty can also intensify these other factors in terms of trapping people in and accentuating their feelings that they are not autonomous agents, capable of bringing change to their lives. "Poor people" are not a static group. In the book, Collins (2014), for example, identifies working age adults, lone parents, single people, childless couples and pensioners as the "new poor". Additionally, having a non-western immigration background, holds the risk of experiencing a double or even multiple disadvantage in terms of exclusion from sports (and other life domains).

The book might be criticized for "only" covering sport and social exclusion in western (high-income) countries, and not explicitly mentioning the rather western geographical scope. In chapter 5, however, Tess Kay shows that poverty carries a female face. She somewhat broadens the geographical scope of the book by noting that $3 / 4$ of the poorest billion people of the world are women, and, as such, women have a greater vulnerability to poverty and from being excluded from sports. Kay further argues that there is a stronger social class effect on women's participation than on men's. High risk groups are women from lower socio-economic groups and women heading a household alone. She states that: "Women predominate among the low paid, they are more reliant on benefits than men...and women are the majority of poor pensioners and parents of poor children". In his final chapter, Collins also strongly argues that while many schemes are mounted to enable more female participation in playing sport, it has rarely looked at the needs, behaviour or attitudes of the most disadvantaged and excluded.

Collins (2014) identifies disabled people as a group that is often confronted with deep social exclusion. The book shows the additive effects of gender and class on disabled people's participation, noting that disabled people are in situations partly determined by social structures, policies and "disabling" attitudes (Collins, 2014 , p. 140). Collins states that disability often implicates extra living, travel and care costs, and consequently, many disabled people and their families depend on welfare benefits, which according to the author makes them by definition "poor". Even those who are active in the labour market, are disproportionately likely to be employed in work that is poorly paid, low-skilled and part-time. Such issues require not only more attention from policymakers and the sport sector, but also from researchers, since "studies on leisure inequality generally omitted any explicit discussion of disability" (p. 147). Just as there is no fixed category of "the poor", there is also no group that can be easily demarcated as the "the disabled". The failure to appreciate the diversity of disabled people means that not all of them benefit from (new) policies to promote social inclusion in sport (p. 139). The book also calls for more research attention to be given to the leisure participation of asylum seekers and refugees. We might also add children and people who are institutionalized, both young and old.

\section{Policy Lessons}

In summary: yes to sustainability and longevity; no to short term projects, which Collins refers to as "initiativitis". This could be the core answer to the question: 
"What is, from a policy perspective, the best way to tackle exclusion from sport and society in the future?". Collins (2014) compellingly asks policymakers to: aspire less to novelty; better resource projects; provide longterm follow-up support, lengthen the policy span to 7 or 10 years; show more commitment with a clearer focus; and be less impatient. In his own words:

"If [sport] is to play a greater role in helping to meet public policy aims to increase participation of excluded groups, its structure needs strengthening, perhaps in clusters, where administration could be consolidated, and where particular clubs could specialise in working with particular groups or levels of performer". (Collins, 2014, p. 229)

More specifically, the book repeatedly focuses on three relevant issues on which sport policies could have a direct impact, namely: transport, leisure cards and multisport clubs. We will briefly touch these three issues. A neglected factor in exclusion from leisure time remains transport. The book shows that for groups living in poverty, transport remains a prominent structural barrier. People living in poverty might not have a car, and public transport may be inaccessible or unavailable at the times necessary to facilitate participation. Even when there is public transport, it may unaffordable or there may be issues of safety involved in terms of using public transport in the evening or at night (e.g., young children or young women). Collins (2014) argues that it is remarkable in the burgeoning geographical, planning, economic and sociological literature on regeneration and urban management how little attention has been given to the ways in which urban planning and transport decision-making affects sports. The book identified the experiences of older people and people with disabilities as particularly precarious in relation to transport barriers.

The second issue is leisure cards (see case study 1 in the book). Collins seems to be a firm believer of the potential of leisure cards in providing sporting opportunities for those who are not able to participate. However, he stresses that social marketing strategies (for example through paid advertising in local media) and managerialist mechanisms need to be used more intensely in order to reach the desired target groups. Further, leisure cards are most useful, according to Collins, when a systematic monitoring and evaluation strategy is present, including the necessary money and personnel to do the monitoring and evaluation.

Thirdly, Collins supports investing in or setting up large multisport clubs. He argues that:

Much larger clubs (averaging 300 but sometimes reaching 3,000 or more members) means that youth leaders, coaches and mentors can be more easily found and dedicated to youth work than in
Britain's small clubs, averaging only about 43 members....Larger size allows specialisation of roles, but also makes the club a more secure place to invest public money in facilities and especially professionals. (Collins, 2014, p. 71)

In light of such sentiments, he argues for two major policy changes. The first suggested policy change is to support the founding of multi-sport clubs in limited places of new development, and the second one is to cluster clubs to gain economies of scale in terms of operating costs, without giving up autonomy. It is not wholly clear what empirical evidence Collins used to formulate these thoughts and policy recommendations. To the book reviewer's knowledge, there is no hard evidence that larger sport clubs are better (or less worse) in terms of combatting social exclusion and including people living in poverty. Secondly, although the clustering of clubs might mean economic gains (by, for example, sharing infrastructure, getting better prices from insurance companies and more subsidies from local governments because of more members), other factors might suffer from such clusters of cooperation, such as accessibility (if activities are centralized) or feelings of belonging (because the groups are bigger and there is no dominant group with one can identify). It could, therefore, be argued that small clubs or associations offer advantages in terms of reaching people living in poverty, which would require targeted policy interventions to unlock their potential. These are, however, all speculations, and all of this would require further research.

All in all, Collins opined that the policy leverages of sport in terms of combatting social exclusion are "puny" and it is more likely that leisure in general offers a potential contribution in dealing with social exclusionary processes and outcomes. The ephemeral impact of sport policy on social exclusion has also been stressed by Coalter (2012). Collins (2014) further states that because of an interplay of multiple constraints, both on an individual and structural level, single policy measures are insufficient to tackle social exclusion, particularly since addressing one constraint merely gives another prominence. This, according to the author, necessitates unprecedented forms of coordinated health, sport, physical activity policies. In other words: the impact of sport on broader processes of social exclusion seems to be non-existent, and the impact of single sport policy measures to combat social exclusion from sport, are at best ephemeral.

\section{Sport an Agent of Change?}

In the fifth chapter, on page 97 more precisely, Collins argues that in sport as elsewhere, formal policies do not guarantee effective action. We might forget it, but long before there was a minister of sport and a sport policy, there were sport associations that offered envi- 
ronments to play sports, and which included and excluded certain groups of people. There is an old Chinese proverb that says that the laws of the emperor are less than the customs of the village. Replace the words "emperor" with sport minister, the "laws" by sport policy and the "village" by sport club, and we might learn from this old Chinese proverb that what policymakers want or put in legislations, may differ very much from day-to-day local sport practices.

Notwithstanding this, sport clubs or associations can take their own measures to combat processes of social exclusion. They can, in other words, be their own agents of change. When referring to sport as a sector, we mean voluntary and professional sport clubs or associations, national sport bodies and local municipal sport services. Following Collins' view on the potential of large multi-sport clubs, such clubs could work (or merge) together in clusters, which would allow them to share expertise, facilities or other (human, social, economic, political) resources, but also broaden and deepen their services both in terms of sport, but also in implementing and coordinating strategies to combat social exclusion. According to Collins (2014) such sport clubs make them more secure places to "invest public money in facilities and especially professionals" (p. 71). What is more, larger sport entities could also have a bigger "say" or "footprint" in local contexts since they would command a greater proportion of local resources. Collins (2014) opined, however, that sport clubs still have a long way to go. He wrote: "While awareness training for staff is now widespread, including amongst volunteers...it is clear that many local sport clubs have not yet taken action to broaden their cultural base" (p. 135). Culture here needs to be understood as broader than ethnic background, but in relation to black and minority ethnic groups (BME), the books argued that: "Good practices to encourage BME groups are similar to those for women: providing role models, programme space and time sympathetically, offering private/segregated sessions providing leadership and outreach worker" (p. 126). Notably, Collins (2014) referred to more publicity and information in BME languages and linking sports to cultural/religious festivals. The book identified seven key drivers for promoting social inclusion, which may serve as an inspirational framework for the sport sector, it should also be viewed as practices to be further tested in a diversity of sport contexts. Collins suggests sports services should: be community driven; empower beneficiaries, make social cohesion an objective; driven more by participants; developed by specialist outreach staff; measured qualitatively; and effectively marketed. However, as he repeatedly emphasises: sport cannot do it alone. As such, sport clubs, national governing bodies and local municipalities need to work together with civil society actors and other municipal services in multiple policies domains such as youth(-work), wel- fare, outreach, education and childcare to address cross-cutting issues associated with social exclusion.

\section{Concluding Thoughts}

Although income-related poverty is, according to the author, at the core of social exclusion, people's own characteristics or unique social circumstances may have divergent impacts on their lives in general, and their sport (non-)involvement in particular. This is illustrated throughout the different chapters of the book and the case-studies. Collins (2014) identified single parent families, ethnic minorities, disabled people and elderly without second or index-linked pensions as disproportionately over-represented in the social group suffering from poverty and social exclusion. Sections in the book dealing with gender issues and people with disabilities clearly illustrate that, in combination with situations of poverty, gender (being a girl/woman) and disability have deep negative multiplier effects on social exclusion and barriers to leisure participation. In addition, Collins (2014) identifies a group that is highly precarious and almost left untouched in sports research, namely refugees and asylum seekers.

Treating the "socially excluded" or "the poor" as one category or as a collection of different welldemarcated sub-categories is problematic, notwithstanding a shared experience of income-related poverty and exclusion from aspects of social life. A young girl growing up in a work-poor household, a young boy living in a household dependent on welfare-benefits due to disabilities of family-members, a young person of non-western ethnic background growing up in a single-parent household or a young asylum seeker in a transit-centre, face both similar and different challenges. Any policy that aims at alleviating social exclusion in relation to sport participation needs to be able to tackle processes of social exclusion across multiple policy domains and with a broad view to those living in poverty and being confronted with social isolation and barriers to full participation in civic life. This also requires that different groups in society have the ability for "self-advocacy" and a strong voice in decision-making processes. The sport world indeed needs to take hard and demanding steps, but such steps should be taken alongside a cross-policy perspective with a real likelihood of being able to address the root causes of poverty and social exclusion. The world of sports has seen enough limited-focus programs (and research) to cope with broad gauge problems (Weiss, 1993), such as poverty and social exclusion. This book serves as a timeless reminder of this message.

\section{Acknowledgements}

I would like to thank Dr. Laura Kelly for her valuable feedback on the text 


\section{Conflict of Interests}

The author declares no conflict of interests.

\section{References}

Chenail, R. (2010). How to read a book like a qualitative researcher. The Qualitative Report, 15(6), 16351642.

Coalter, F. (2012). Game plan and the spirit level: The class ceiling and the limits of sports policy? International Journal of Sport Policy and Politics, 5(1), 3-19.

Collins, M. (2003). Sport and social exclusion.
Routlegde: London.

Collins, M. (2014). Sport and social inclusion (2nd ed.). Routlegde: London

Haudenhuyse, R., Theeboom, M. \& Nols, Z. (2012) Sports-based interventions for socially vulnerable youth: Towards well-defined interventions with easy-to follow outcomes? International Review for the Sociology of Sport, 48 (4), 471-484.

Weiss, C. (1993). Where politics and evaluation research meet. American Journal of Evaluation, 14(1), 93-106. Retrieved from http://www.sfu.ca/ palys/ Weiss-1973-WherePoliticsAndEvaluationMeet.pdf

\section{About the Author}

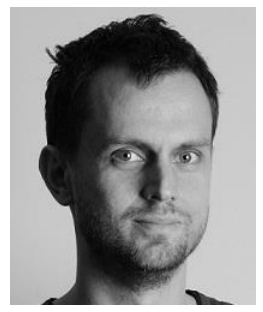

\section{Dr. Reinhard Haudenhuyse}

Reinhard Haudenhuyse has a Master's degree in Physical Education. He holds an additional Master's degree in Conflict and Development (Third World Studies). In 2012, Reinhard received his PhD, entitled "The Potential of Sports for Socially Vulnerable Youth", in Physical Education and Movement Sciences at the Vrije Universiteit Brussel. His work focuses on the impact of sport on an individual, group and societal level, with specific attention to people living in disadvantaged and precarious situations. 